\title{
Archivo General de Simancas: Ios mapas más antiguos de Andalucía
}

Jaime Sainz Guerra, Archivo General de Simancas

\section{EL ARCHIVO GENERAL DE SIMANCAS}

El origen del Archivo General de Simancas hay que enmarcarlo en los inicios del Estado Moderno, en la burocratización administrativa. La idea de recoger y guardar la documentación no es sólo idea de los reyes sino que nace de la propia administración. El creador del archivo fue Carlos V (1540), aunque fue Felipe II quien desarrolló todo el proyecto archivistico, que culminó en las Instrucciones para el gobierno del Archivo de Simancas (1588).

El archivo comenzó inmediatamente a recibir en sucesivas remesas los papeles procedentes de los órganos centrales de la Monarquía hispánica, los Consejos en la época de los Austrias y las Secretarías de Despacho en la época borbónica (RODRÍGUEZ DE DIEGO, 2005: 352). Dentro de esta documentación administrativa se encuentran también los mapas y los planos. Los mapas permiten la representación gráfica de realidades espaciales que el hombre no podía percibir sin su ayuda. Se utilizaron para conocer el espacio real y, en cierta manera, lo sustituyeron o reemplazaron (BOUZA ÁLVAREZ, 1995: 13).

Los reyes eran conscientes del potencial de los mapas en el proceso del gobierno. Fernando el Católico en la Corona de Aragón tenía cartógrafos en su corte e Isabel conocía la importancia de la cartografía en sus aventuras en el descubrimiento de un nuevo mundo. Carlos $V$ también fue muy consciente del valor de los mapas y Felipe II se consagró con dedicación a la producción de un buen mapa de la Península. Ambos estaban rodeados por nobles y consejeros que usaron y recolectaron mapas, como también lo hicieron sus sucesores (BUISSERET, 2007).

\section{LA COLECCIÓN DE MAPAS, PLANOS Y DIBUJOS}

Esta colección facticia, creada por el desglose del material cartográfico de la documentación original por necesidades de conservación, es de creación reciente. En 1923 no existía más que una carpeta grande en la que se guardaban unos cuantos mapas y planos separados de los legajos, aunque no constaba cuándo se habian separado ni tampoco el motivo o la finalidad perseguidos (GUÍA, 1992: 341).

Cuando se pensó seriamente en organizar esta colección fue hacia 1932, fecha en la que se adquiere el primer planero para guardar con las debidas garantías los documentos, que casi siempre estaban plegados en los legajos. Buena prueba de que se continúa con la búsqueda y separación de este tipo de documentos es la adquisición de un segundo planero en 1934.

El desglose de estos documentos de sus legajos se realizaba con el debido cuidado, dejando en el legajo un testigo con la descripción del documento y la nueva signatura en la colección de mapas, planos y dibujos, anotando al mismo tiempo en el documento desglosado el legajo de procedencia y la signatura. Se redactaba también la correspondiente ficha para un indice alfabético de nombres geográficos, asuntos y autores. En la década de los 60 la colección de mapas constaba de unos 2.500 items, repartidos en dos planeros.

Actualmente la colección cuenta con alrededor de 8.000 documentos, en su mayoría cartográficos, aunque también los hay gráficos (grabados, dibujos...) y tridimensionales (telas, prendas de vestir, cuerdas, puntas, monedas...). Su catálogo es de acceso público y desde él se puede acceder tanto a las descripciones como a la digitalización de los fondos (http://www.mcu.es/ccbae/ es/mapas/principal.cmd).

La mayor parte de los planos existentes en Simancas proviene de la documentación producida por el Consejo de Estado, el Consejo de Guerra y el de Hacienda en los siglos XVI y XVII y por las Secretaría de Despacho de Estado, Secretarias de Guerra y Marina y Secretaría de Hacienda, en el siglo XVIII.

La materia de la mayoría de los mapas es la militar, fortificaciones de todo tipo (murallas, arsenales, castillos...), puertos y otras construcciones militares (almacenes, polvorines...). La temática civil se centra en las obras hidráulicas (puentes, presas, acueductos, abastecimientos de agua...) y sobre todo en el siglo XVIII en el desarrollo de una incipiente industria (textil, de tabaco, salinas...).

\section{ANDALUCÍA EN LA COLECCIÓN DE MAPAS, PLANOS Y DIBUJOS DEL ARCHIVO GENERAL DE SIMANCAS}

De los más de 5.000 mapas y planos de la colección, 1.080 pertenecen a Andalucía. Son planos en su mayor parte del siglo $\mathrm{XVIII}$, en los que predomina, como en el resto de los planos, la 


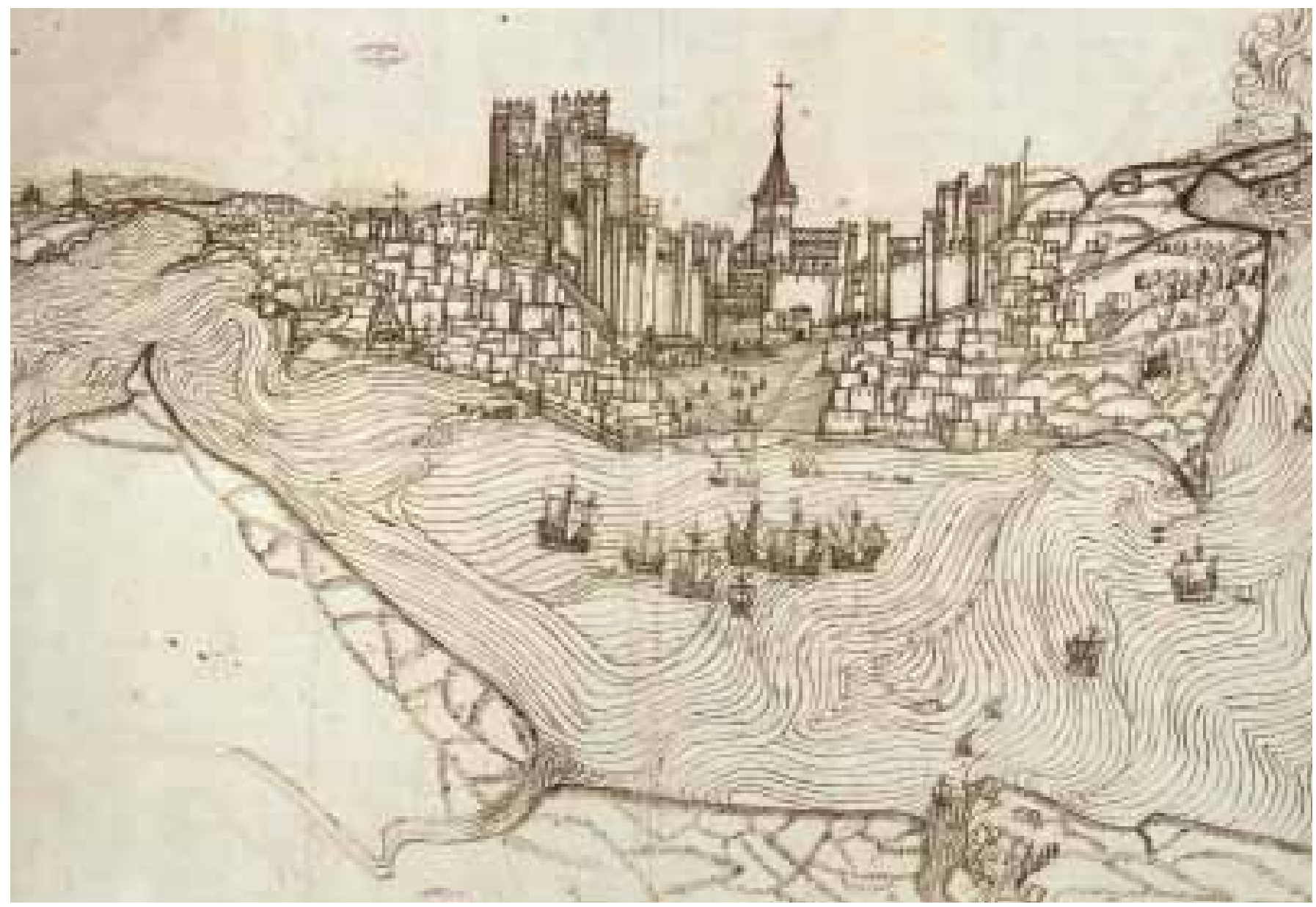

Dibujo de la ciudad de Cádiz sobre un postigo abierto en la fortaleza y en el muro[1513?]. Fuente: España. Ministerio de Cultura. Archivo General de Simancas, MPO,25,47

indole defensiva. Planos de fortificaciones, sobre todo costeras, en los que se refleja la preocupación por las incursiones de los piratas berberiscos, ingleses y holandeses.

Los fondos documentales de Simancas están organizados en secciones. Secretaria de Guerra es la sección de la que procede la mayor parte de los planos. De los 1.080 planos existentes de Andalucía, 835 proceden de esta sección. Se detallan con especial atención las fortificaciones costeras (Cádiz, Algeciras, Málaga, Almería...). También nos encontramos planos que representan la estructura económica del momento, procedentes en su mayor parte de las secciones de Hacienda. En especial destaca la Dirección General de Rentas (22 planos), donde aparecen planos de salinas, como la de Osuna, fábricas de municiones (Linares), fábricas de tabaco (Sevilla), términos municipales por venta de jurisdicciones... Los procedentes de las secciones Consejo y Juntas de Hacienda (8) y de Expedientes de Hacienda (6) están en su mayor parte realizados para controlar los términos municipales. De Secretaria y Superintendencia de Hacienda (30) aparecen los primeros planos de carreteras, fábricas de tabaco y obras hidráulicas (pantanos, abastecimiento de agua, puentes...).

De la Cámara de Castilla sobresale un plano de Cádiz (MPD, 25, 47), el más antiguo de Andalucia existente en la colección de Simancas. Es una vista del 1513 de la ciudad de Cádiz en la que aparece la muralla y los edificios más relevantes, procedente de un pleito originado por la apertura de un postigo en la muralla. Se trata de una bella representación de la bahía de Cádiz, con los barcos, la muralla y la ciudad. Puede pertenecer a la tradición cartográfica medieval sin referencias a la teoría astronómica, matemática o cartográfica.

A la sección Casa y Sitios Reales (11) pertenecen los planos de los palacios reales de Granada y Sevilla, asi como el sitio real del Soto de Roma y otras zonas de propiedad real. De la sección de Guerra y Marina, antecesora de la Secretaría de Guerra, nos encontramos con 47 planos, en su mayor parte fortificaciones (Cádiz, Gibraltar, Almeria, Huelva...). Los planos del Arsenal de la Carraca en Cádiz forman el núcleo principal de la documentación procedente de la Secretaría de Marina (79), junto con los de la Bahía de Cádiz, con sus fortificaciones y edificios militares.

\section{Bibliografía}

BOUZA ÁLVAREZ, F. J. (1995) Una histoire de mapes, una história en mapes. En De Mercator a Blaeu : Espanya i l'Edat d'Or de la cartografia a les disset Provincies dels Països Baixos. Barcelona: Institut Cartográfic de Catalunya, Fundación Carlos de Amberes, 1995

BUISSERET, D. (2007) Spanish peninsular cartography, 1500-1700. En WOODWARD, D. The history of cartography. III: cartography in the European Renaissance. Part 1/ edited by. Chicago: University of Chicago Press, 2007 GuíA del Investigador. Madrid: Archivo General de Simancas, 1992 RODRÍGUEZ DE DIEGO, J. L. (2005) La Sección de Mapas y Planos del Archivo General de Simancas. En CÁMARA MUÑOZ, A. (coord.) Los ingenieros militares de la monarquía hispánica en lo siglos XVII y XVIII. Madrid: Ministerio de Defensa, Centro de Estudios Europa Hispánica, 2005, pp. 351-359 